\title{
Abstract
}

\section{Familial Breast Cancer in Southern Finland}

\author{
Hannaleena Eerola, Carl Blomqvist, \\ Seppo Pyrhönen and Heli Nevanlinna \\ Departments of Oncology, Obstetrics and \\ Gynecology, Helsinki University Central \\ Hospital, Helsinki, Finland
}

We evaluate here the prevalence of hereditary and familial breast cancer in Southern Finland and the accuracy of patient reports of family history.

Breast cancer patients from three different cohorts: young (170), bilateral (118), and unselected (1282) patients, were interviewed for family history. Families fulfilling one uniform selection criterion (at least three first- or seconddegree relatives with breast or ovarian cancer) were considered hereditary. The genealogy of these families was confirmed through church parish registries and Population Register Center and cancer diagnoses through Finnish Cancer Registry.

Altogether, any family history was reported by about $30 \%$ of the patients. 100 families fulfilled the selection criterion: $9.4 \%$ of the young, $8.5 \%$ of the bilateral, and $6.9 \%$ of the unselected patients. $20 \%$ of these families also included ovarian cancer cases. Index patients reported $86 \%$ of all confirmed cancer diagnoses $(99.5 \%$ among first- and second-degree relatives) and primary site was correctly identified in $95 \%$ of the reported cases. However, only $61 \%$ of cancer diagnoses of more distant relatives (3rd degree, e.g. cousins) were reported by the patients these may be important also when considering criteria for diagnostic testing.

Although the reported family history is quite accurate, the level of error should be considered in epidemiological studies and verification of the cancer diagnoses is important when deciding clinical management. 


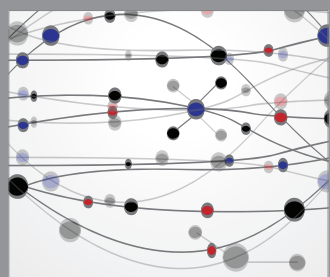

The Scientific World Journal
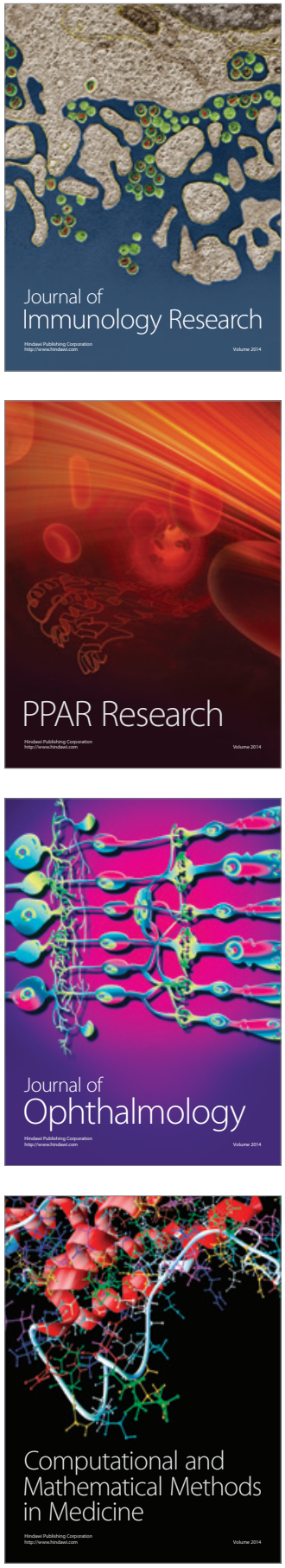

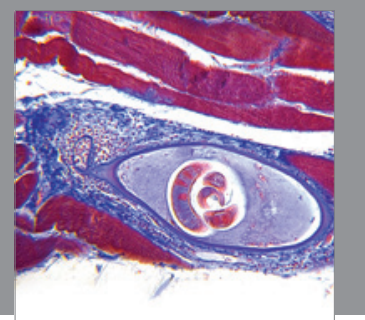

Gastroenterology

Research and Practice
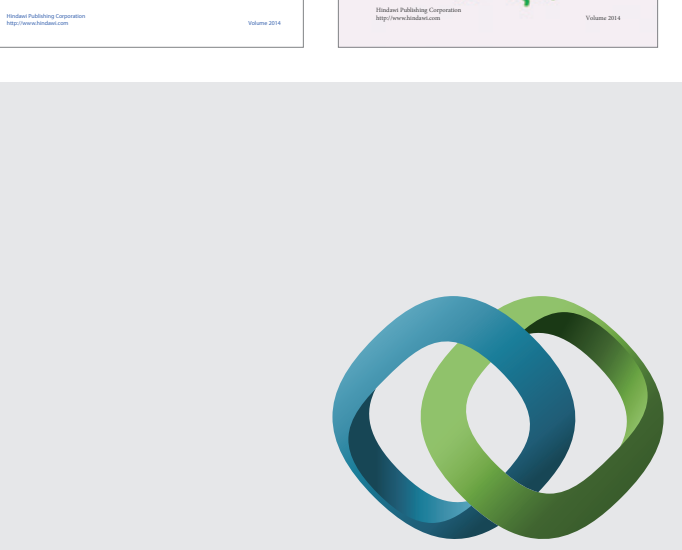

\section{Hindawi}

Submit your manuscripts at

http://www.hindawi.com
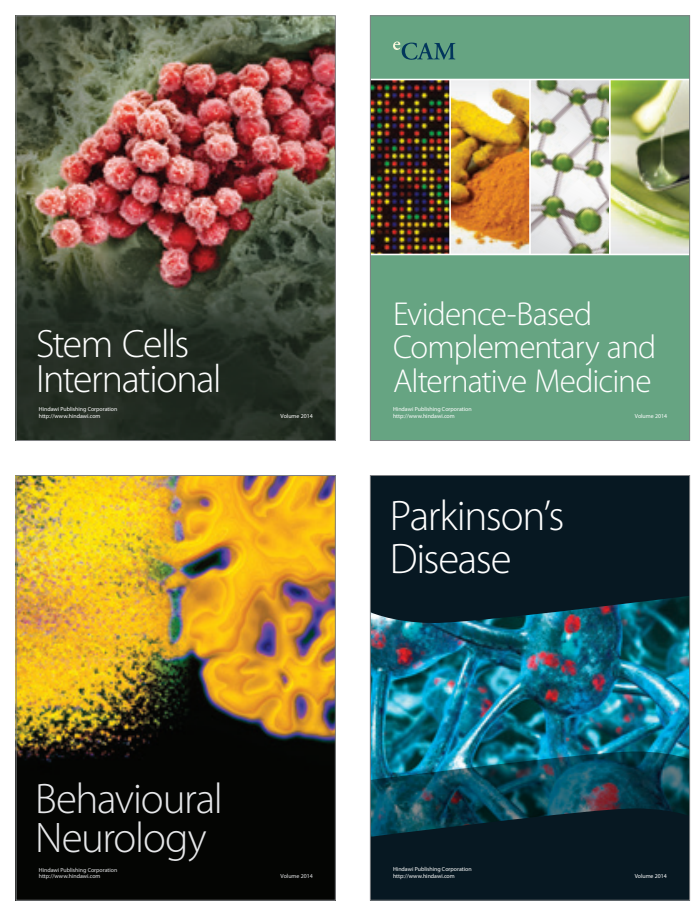

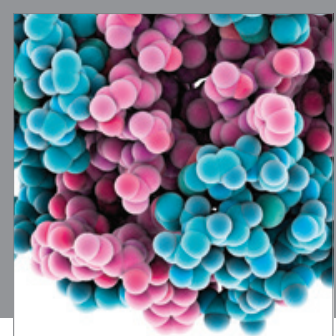

Journal of
Diabetes Research

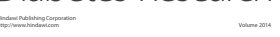

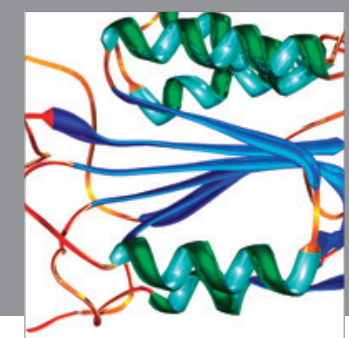

Disease Markers
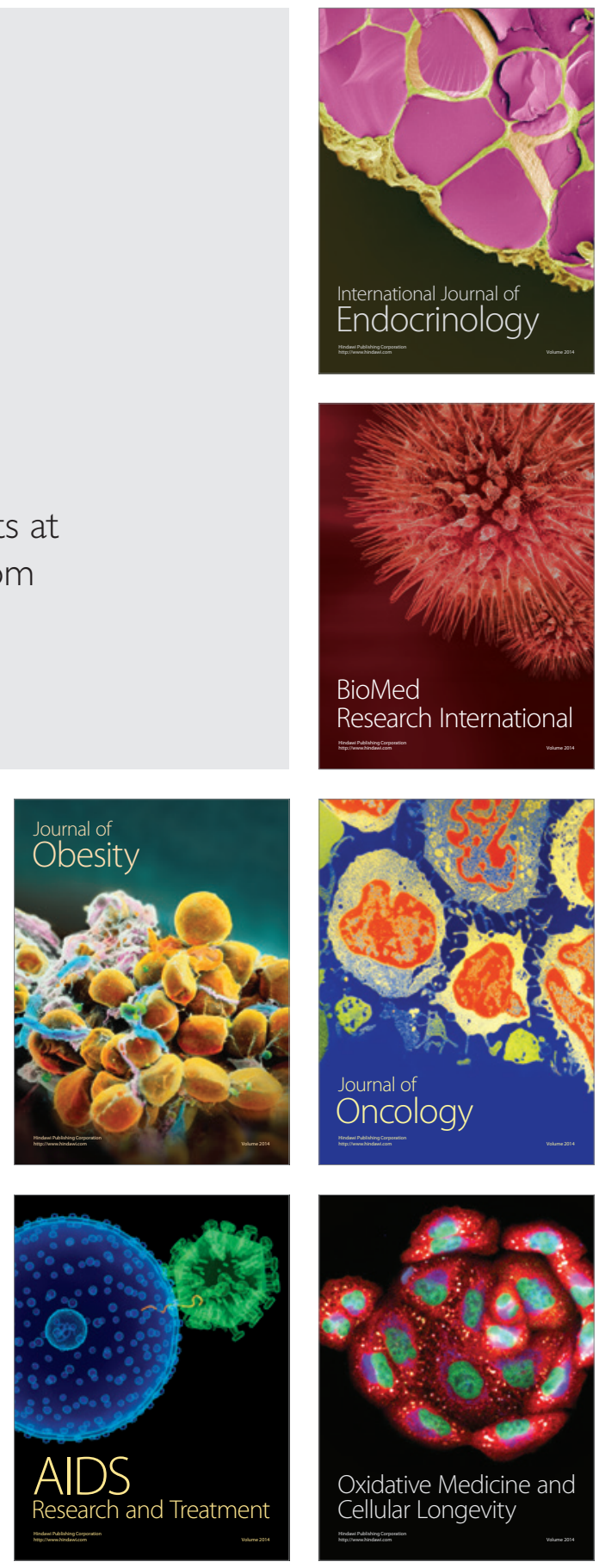